Удк 005.322:316.46

\title{
КУЛЬТУРНО-ЦЕННОСТНОЕ ИЗМЕРЕНИЕ ЛИДЕРСТВА: КОНТЕКСТ КРЕАТИВНОГО ОБЩЕСТВА КАК ОБЩЕСТВА БЛАГОПОЛУЧИЯ
}

\author{
Кривовяз Наталья Викторовна, \\ awatanchik@yandex.ru \\ Рябченко Даниил Олегович, \\ rd@latat.org \\ Национальный исследовательский Томский политехнический университет, \\ Россия, 634050, г. Томск, пр. Ленина, 30.
}

Кривовяз Наталья Викторовна, кандидат экономических наук, доцент Школы инженерного предпринимательства Национального исследовательского Томского политехнического университета.

Рябченко Даниил Олегович, аспирант Школы инженерного предпринимательства Национального исследовательского Томского политехнического университета.

Дан анализ культурно-ценностной парадигмы феномена лидерства. Лидер - «интегральный человек интегрального мира», служащий функциональности ведомых, способный видеть перспективу. Субъективность лидерства представлена материалом ценностной конщепции «Обслуживающего лидерства» Р. Гринлифа, в которой феномен обслуживающего лидерства представлен как легитимированный этническими ограничениями. Исследована система ценностных характеристик «обслуживающего» лидера. Ценности интерпретированы как субъектно-образующий фактор системы «лидер-ведомые», как консолидирующий фактор, назначением которого является обеспечение интегрированности и устойчивости сообщества.

Ключевые слова: Лидер, лидерство, управление, ценности, культурно-ценностное измерение лидерства, лидер-слуга, обслуживающее лидерство, служение как миссия, «философия в действии».

А. Менегетти в бестселлере «Психология личности» охарактеризовал лидера как человека, научившегося живо чувствовать мир, умеющего реализовывать личный и социальный рост в целях глобального прогресса сообщества. В феномене лидерства заключены обращение на себя внимания, способность лидера служить функциональности ведомых. А. Менегетти назвал лидера «интегральным человеком для интегрального мира» - лидер, поднимаясь над своей зрелостью, обретает возможность видеть перспективу [1]. В гуманитарном знании тема лидерства сегодня вышла за пределы сугубо психологического изучения в силу того, что лидерство как феномен превращено в объект редкостного и предельного интереса общества. Этот феномен интересен как явление системы организационной культуры, как явление сегмента политической сферы. Лидерами называют глав государств, к лидерам относят страны и регионы, своих лидеров ценят компании - речь идет о лидирующих позициях в сегменте рынка [2]. Интерес к проблеме лидерства обусловлен и тем, что истории общества знаком и феномен так называемого деструктивного лидерства и этот феномен по-прежнему мало изучен. Сказанным обусловлена ситуация, достаточно парадоксальная по своей сути: вечный феномен, играющий огромную роль в человеческом сообществе, оказался во многом нераскрытым в своей основе. Более того, исследующие природу лидерства фиксируют факт сужения аналитического интереса к обозначенной проблеме [3, 4]. 
В огромном массиве исследований, ранее проделанных и посвященных лидерству, считает автор, проигнорированы возможности системной методологии. Этот пробел мы постараемся восполнить, обратив внимание к субъектности лидерства. Вопрос невозможно решить, не сделав культурно-ценностного измерения феномена лидерства. Выбрав предметом исследования ценностную природу лидерства, мы тем самым предпримем попытку решения ряда задач, ориентированных на сферу практики, в числе которых - задача оптимизации управленческих процессов. Реконструкция системы ценностей, присущих лидеру, обусловит понимание специфики того основания, на котором стоится деятельность эффективного лидерства.

Исходной в анализе ценностного смысла феномена лидерства является, на наш взгляд, идея, ориентированная на понимание роли ценностей как субъектнообразующего фактора системы «лидер-ведомые». Эта идея заключена в понимании системы общеразделяемых ценностей как консолидирующего фактора и ценного катализатора, назначением которой является обеспечение интегрированности и устойчивой социальной общности (в последних трудах XX в. вплотную подошли к осознанию этой идеи Р. Гринлиф и К. Ходжкинсон, а позже - Г. Фейрхольм и С. и Г. Кучмарские [5-7]). Под ценностями будем понимать одну из основных понятийных универсальных философий, обозначающую в самом общем виде невербализируемую составляющую наиболее глубинного слоя интернациональной структуры личности. Ценности, по утверждению В.К. Шохина, констатируют внутренний мир личности, как «уникальносубъективное бытие». Ценность - форма отношения к общественным образцам культуры и тем возможностям, сознание которых определяет способность личности проектировать будущее, оценивать «иное», сохранять прошлое (В.Н. Плотников). Ранее в «Никомаховой этике» Аристотель назвал ценность первопринципом и интерпретировал ее как разновидность блага.

В ценностных теориях лидерства последних десятилетий XX в. особое место занимает теория «обслуживающего лидерства» (Р. Грин) мира (servant_leadership), не утратившая и сегодня своей значимости. Термин «обслуживающее лидерство» впервые употреблен Р. Гринлифом в монографии «Смута как лидер», хотя и в более поздних работах автор обращается к этой идее, следующим образом раскрывая ее смысловое значение: лидер служит сообществу, ведомым, и это определяет его величие. Подлинно лидерские качества проявляются тогда, когда идеей, определяющей вектор поведенческой деятельности лидера, является желание помочь $[8,9]$. Аналитиком вводится понятие «обслуживающее сообщество», подразумевающее расширяющееся обслуживание субъектов организационного процесса и процесс принятия решений. Лидер выполняет функции слуги, реализуя свою миссию через служение, лидер удовлетворяет систему запросов ведомых-последователей, однако требует быть учтенным немаловажный фактор, смысл которого заключается в желании ведомых быть обслуживаемыми [10]. И лишь тогда, когда очевидно сражение этих двух факторов (представление лидера о своей миссии (служение ведомым) и желание ведомых быть обслуживаемыми), можно говорить о реализованности миссии лидера и результате этой миссии. Этим результатом является «обслуживающее сообщество». Описанная ситуация, понимание существа осуществляемых процессов - это основание, которое позволило Р. Гринлифу охарактеризовать феномен обслуживающего лидерства как легитимированную этническими ограничениями. Эти ограничения ориентированы на достижение эффективного результата. Р. Гринлифом сформулирована и система прагматических критериев достижения результата: результат может быть получен только через грамотное и эффективное использование власти [11]. 
В свою очередь, условием выполнения лидерской миссии (эта миссия выражена в служении) выступают характеристики обслуживающего лидера. Этими характеристиками являются [12]:

- коммуникативные навыки лидера, его умение служить, воспринимать смысл не только сказанного, но и того, что демонстрируется невербальной компонентой, способность лидера принимать решения и подвергать рефлексии получаемое знание;

- обладание чувством эмпатии, способность понимания внутреннего мира Другого, желание признания уникальности, непохожести Другого, в том числе признание неотчуждаемого права Другого на эту уникальность и непохожесть. Обладая развитым чувством эмпатии, способностью понимания внутреннего мира Другого, лидер помогает последователям-ведомым освободиться от груза эмоциональных проблем;

- обладание такой системой знания, которая позволяет лидеру не выходить на целостную систему организационной этики и ценностей, результатом чего является разносторонняя оценка ситуации, требующей принятия решений;

- обслуживающий лидер (Лидер-слуга) эффективен в создании консенсуса в сообществе, при этом лидеру присуща способность добиваться согласия, делая основным метод убеждения (в этом основное различие традиционной авторитарной модели и модели обслуживающего лидерства);

- способность владения концептуальной перспективы к концептуальному мышлению; детальное видение различия каждодневных проблем и проблем стратегически значимых, умение находить равновесие этих одинаково значимых в деятельности лидера проблем;

- способность к целеполаганию, к предвидению результатов своих действий; в основании этой способности - умение критически оценивать прошлое, правильно интерпретировать настоящее, интуитивно верно оценивать последствия принятых с помощью экспертного знания решения;

- стремление к максимально возможному удовлетворению потребностей ведомого сообщества;

- способность поощрять профессиональный, духовный, индивидуальный род ведомых, основанная на понимании уникальности Другого;

- лишь реализация всего перечисленного - условие существования «обслуживающего сообщества» как эффективно работающего сообщества.

И хотя модель «обслуживающего лидерства» Р. Гринлифа может во многих смыслах и отношениях служить идеалом, реализация принципов, заложенных в основание этой модели, достаточно трудна и сложна. Мы принимаем логику В.Ф. Суранова в той части его рассуждений, где определяются условия, при которых возможна эффективная реализация принципов ценностной модели [13]. В числе этих условий - зрелая структура сообщества (организации), зрелая система взаимоотношений, достаточный уровень компетентности субъектов сообщества. Модель Р. Гринлифа может быть не всегда использована, чему мешает опосредованный тип общения, невозможность постоянного общения с ведомым, что неизбежно сказывается на результатах коммуникативных отношений $[14,15]$.

Вместе с тем вектор этической направленности действий лидера на субъекты управления, привлекательный сам по себе, обусловил возникновение в американской версии теории лидерства ряда ценностных концепций. Такой стала концепция ценностного лидерства К. Ходжкинсона, посвященная выявлению культурно-ценностного измерения лидерства и роли ценностей в консолидации системы «лидер-последователи». К. Ходжкинсон в ряде своих работ не просто методологически обосновал роль ценно- 
сти в процессах администрирования и управления, но сумел показать: именно эти процессы обнаруживают потенциал отношений лидирования в механизмах стратегии администрирования и управления, проявляя себя как «философия в действии» и формируя вектор ценностных проявлений лидерства, ориентированных на перспективное развитие [16-18].

\section{СПИСОК ЛИТЕРАТУРЫ}

1. Менегетти А. Психология лидера. - М.: ННБФ «Онтопсихология», 2002. - 256 с.

2. Roman F., Peterson M., Koster A. The rise of Generation C: how to prepare for the connected generation's transformation of the consumer and business landscape. - NY.: Strategy + Business, 2011. -8 p.

3. Занковский А.Н. Организационная психология. - М.: Форум, 2009. - 646 с.

4. Занковский А.Н. Психология лидера: от поведенческой модели к культурно-ценностной парадигме. - М.: Издательство института психологии РАН, 2011. - 295 с.

5. Boynton Andy, Bill Fischer, Bill Bole. The idea hunter: how to find the best ideas and make them happen. San Francisco, CA: Jossey-Bass, 2011. - 192 p.

6. Bruno S. Sergi. Putin's and Russian-led Eurasian Economic Union: a hybrid half-economics and halfpolitical «Janus Bifrons» // Journal of Eurasian Studies. - 2018. - V. 9. - Iss. 1. URL: https://www.researchgate.net/publication/322409105_Putin\%27s_and_Russian-

led_Eurasian_Economic_Union_A_hybrid_half-economics_and_half-political_Ianus_Bifrons (дата обращения: 11.01.2021).

7. Salkowitz R. Young world rising: how youth technology and entrepreneurship are changing the world from the bottom up. - New York: Wiley, 2010. - 224 p.

8. Зоткин А.А. Информационное господство элит в условиях ослабления национальных государств // Власть и элиты. - 2015. - Т. 2. - С. 73-92.

9. Сидоренко Е.В. Матрица лидерства // Национальный психоматический журнал. - 2007. - № 1 (2). C. $128-131$.

10. Петренко В.Ф. Многомерное сознание. Психосемантическая парадигма. - М.: Новый хронограф, 2009. $-440 \mathrm{c}$.

11. Мацумото Д. Человек, культура, психология. - СПб.: Прайм-Еврознание, 2010. -647 с.

12. Вильякайнен Пекка А., Мюллер-Эберстайн М. Без страха. Лидеры бизнеса в цифровую эпоху. - М.: Олимп-Бизнес, 2015. - 400 с.

13. Негруль С.В. Формирование региональных элит: ценности и идеология: дис. канд. социол. наук. Томск, 2004. - $182 \mathrm{c}$.

14. Rudd C. Agile innovation, or how to design and build a 100 MPG road car in 3 months. URL: https://www.solutionsiq.com/resource/blog-post/agile-innovation-or-how-to-design-and-build-a-100-mpgroad-car-in-3-months/ (дата обращения: 11.01.2021).

15. Clarkin L., Holmes J. Enterprise Mashups. URL: http://msdn.microsoft.com/enus/architecture/bb906060 (дата обращения: 11.01.2021).

16. Коллинс Д. От хорошего к великому. Почему одни компании совершают рывок, а другие нет. - М.: Манн, Иванов и Фербер, 2014. - 384 с.

17. Collins J. How the mighty fall: and why some companies never give I. - New York: Jim Collins, 2009. $240 \mathrm{p}$.

18. Grossman L. 2045: the year man becomes immortal. URL: https://ru.scribd.com/document/50201914/2045The-Year-Man-Becomes-Immortal (дата обращения 11.01.2021).

Поступила 15.01.2021 г. 
UDC 005.322:316.46

\title{
CULTURAL AND VALUE DIMENSION OF LEADERSHIP: CONTEXT OF THE CREATIVE SOCIETY AS A WELL-BEING SOCIETY
}

\author{
Natalia V. Krivovyaz, \\ awatanchik@yandex.ru \\ Daniil 0. Ryabchenko, \\ rd@latat.org \\ National Research Tomsk Polytechnic University, \\ 30, Lenin avenue, Tomsk, 634050, Russia.
}

Natalia V. Krivovyaz, Cand. Sc., National Research Tomsk Polytechnic University.

Daniil O. Ryabchenko, graduate student, National Research Tomsk Polytechnic University.

The article analyzes the cultural and value paradigm of the leadership phenomenon. A leader is an «integral person of the integral world», serving the functionality of the followers, able to see the perspective. The subjectivity of leadership is represented by the material of the value concept of «Serving Leadership» by R. Greenleaf, in which the phenomenon of servicing leadership is presented as legitimized by ethnic restrictions. The system of value characteristics of the "serving» leader is investigated. Values are interpreted as a subjectforming factor of the «leader-follower» system, as a consolidating factor, the purpose of which is to ensure the integration and sustainability of the community.

Key words: Leader, leadership, management, values, cultural and value dimension of leadership, leaderservant, service leadership, service as a mission, «philosophy in action».

\section{REFERENCES}

1. Menegetti A. Psikhologiya lidera [Leader's Psychology]. Moscow, Ontopsychology Publ., 2002. 256 p.

2. Roman F., Peterson M., Koster A. The rise of Generation C: how to prepare for the connected generation's transformation of the consumer and business landscape. NY., Strategy + Business, 2011. 8 p.

3. Zankovskiy A.N. Organizatsionnaya psikhologiya [Organizational psychology]. Moscow, Forum Publ., 2009. $646 \mathrm{p}$.

4. Zankovskiy A.N. Psikhologiya lidera: ot povedencheskoy modeli k kulturno-tsennostnoy paradigme [Leader psychology: from a behavioral model to a cultural and value paradigm]. Moscow, Institute of Psychology of the Russian Academy of Sciences Publ. house, 2011.295 p.

5. Boynton Andy, Bill Fischer, Bill Bole. The idea hunter: how to find the best ideas and make them happen. San Francisco, CA, Jossey-Bass, 2011. 192 p.

6. Bruno S. Sergi. Putin's and Russian-led Eurasian Economic Union: A hybrid half-economics and halfpolitical «Janus Bifrons». Journal of Eurasian Studies, 2018, vol. 9, Iss. 1. Available at: https://www.researchgate.net/publication/322409105_Putin\%27s_and_Russian-

led_Eurasian_Economic_Union_A_hybrid_half-economics_and_half-political_Ianus_Bifrons (accessed 11 January 2021).

7. Salkowitz R. Young world rising: how youth technology and entrepreneurship are changing the world from the bottom up. New York, Wiley, 2010. 224 p.

8. Zotkin A.A. Informatsionnoe gospodstvo elit $\mathrm{v}$ usloviyakh oslableniya natsionalnykh gosudarstv [Information dominance of elites in conditions of weakening of national states]. Vlast $i$ elity, 2015, vol. 2, pp. 73-92.

9. Sidorenko E.V. Matritsa liderstva [Leadership matrix]. Natsionalny psikhomaticheskiy zhurnal, 2007, no. 1 (2), pp. $128-131$.

10. Petrenko V.F. Mnogomernoe soznanie. Psikhosemanticheskaya paradigma [Multidimensional consciousness. Psychosemantic paradigm]. Moscow, Novy khronograf Publ., 2009. 440 p. 
11. Matsumoto D. Chelovek, kultura, psikhologiya [Man, culture, psychology]. St. Petersburg, PraymYevroznaniye Publ., 2010. 647 p.

12. Vilyakaynen P.A., Myuller-Eberstayn M. Bez strakha. Lidery biznesa v tsifrovuyu epokhu [Without fear. Business leaders in the digital age]. Moscow, Olimp-Biznes Publ., 2015. 400 p.

13. Negrul S.V. Formirovanie regionalnykh elit: tsennosti i ideologiya. Dis. Kand. nauk [Formation of regional elites: values and ideology. Cand. Diss.]. Tomsk, 2004. 182 p.

14. Rudd C. Agile innovation, or how to design and build a 100 MPG road car in 3 months. Available at: https://www.solutionsiq.com/resource/blog-post/agile-innovation-or-how-to-design-and-build-a-100-mpgroad-car-in-3-months/ (accessed 11 January 2021).

15. Clarkin L., Holmes J. Enterprise Mashups. Available at: http://msdn.microsoft.com/enus/architecture/bb906060 (accessed 11 January 2021).

16. Kollins D. Ot khoroshego k velikomu. Pochemu odni kompanii sovershayut ryvok, a drugie net [From good to great. Why some companies are making a leap and others are not]. Moscow, Mann, Ivanov i Ferber Publ., 2014. 384 p.

17. Collins J. How the mighty fall: and why some companies never give I. New York, JimCollins, 2009. 240 p.

18. Grossman L. 2045: the year man becomes immortal. Available at: https://ru.scribd.com/document/50201914/2045-The-Year-Man-Becomes-Immortal (accessed 11 January 2021).

Received: 15 January 2021. 